\title{
Relevance of Small Laboratory Animals as Models in Translational Research: Challenges and Road Ahead
}

\author{
Ejaz Ahmad Siddiqui ${ }^{1}$, Pankaj Jagdale ${ }^{2}$, Kedar Ahire ${ }^{3}$, Sachin Jadhav ${ }^{4}$, Shadab Ali Khan ${ }^{1}$, Sidharth Bhosle ${ }^{1}$, \\ Anirban Pal ${ }^{5}$, Pallavi Jamdagni ${ }^{6}$, Bhushan Chaudhari ${ }^{{ }^{*}}$ \\ ${ }^{1}$ Division of Biochemical Sciences, CSIR-National Chemical Laboratory, Pune -411008 (M.S), India. ${ }^{2}$ CSIR-Indian Institute of Toxicology Research, \\ Lucknow-226001 (UP), India. ${ }^{3}$ Department of Zoology, Savitribai Phule Pune University, Pune-411007 (MS), India. ${ }^{4}$ Department of Animal \\ Facility,Agharkar Research Institute, Pune-411004 (MS), India. ${ }^{5}$ CSIR-Central Institute of Medicinal and Aromatic Plants, Lucknow-226015 (UP),India \\ ${ }^{6}$ National Research Institute of Basic Ayurvedic Sciences, Pune-411038 (MS), India.
}

\begin{tabular}{|c|c|}
\hline ARTICLE INFO & ABSTRACT \\
\hline $\begin{array}{l}\text { Article history: } \\
\text { Received on: } 02 / 02 / 2016 \\
\text { Revised on: } 28 / 02 / 2016 \\
\text { Accepted on: } 24 / 03 / 2016 \\
\text { Available online: } 28 / 05 / 2016 \\
\end{array}$ & $\begin{array}{l}\text { Translational research using small laboratory animals is being done to demonstrate proof of concept, to study } \\
\text { pharmacokinetics as well as to understand efficacy and safety of new drug molecules. During the evaluation of a } \\
\text { drug candidate, the assessment of efficacy and safety is normally performed in different experiments using } \\
\text { various animal models. In such experiments, efficacy is assessed by mimicking the disease state in animal model } \\
\text { while safety is investigated in healthy animals. Inventing new drugs using biotechnological and }\end{array}$ \\
\hline $\begin{array}{l}\text { Key words: } \\
\text { Animal models, translational } \\
\text { research, drug discovery, } \\
\text { transgenic animals. }\end{array}$ & $\begin{array}{l}\text { nanotechnological approaches is becoming a major thrust area in drug research. Apart from this, the } \\
\text { development of medicine from traditional knowledge like Ayurveda has emerged as major area for drug } \\
\text { industry. Use of conventional in-vivo approaches may not prove useful to answer many questions. } \\
\text { Transgenic/knock-out/knock-in animals are now getting space in pharmaceutical research for target } \\
\text { identification and validation. Predictability of in-vivo research depends on scientific protocols and methods } \\
\text { adopted for model selection and development. Various alternative approaches for in-vivo research are being } \\
\text { followed. It is a fact that no animal model is } 100 \% \text { capable of mimicking the complex human body but still, } \\
\text { researchers have not yet found any alternative model which can completely replace in-vivo models. This review } \\
\text { is a holistic approach explaining the various animal models being used for translational research, animal ethical } \\
\text { issues, alternative approaches available and provides a critical analysis of major issues/challenges faced in } \\
\text { translational research using in-vivo approaches. }\end{array}$ \\
\hline
\end{tabular}

\section{INTRODUCTION}

Animals are biologically and physiologically similar to humans. It has been stated that, chimpanzees share more than $99 \%$ of DNA with humans and mice share more than $98 \%$ DNA with humans. Hence, animals are susceptible to many of the same health problems as humans. Small laboratory animals have relatively much shorter life cycle as compared to humans and hence, they can be studied throughout their whole life span or even for several generations. In addition, environmental

\footnotetext{
* Corresponding Author

Bhushan Chaudhari, Division of Biochemical Sciences, CSIR-National

Chemical Laboratory, Pune -411008 (M.S), India.

Email: bpchaudhari@gmail.com
}

conditions like diet, temperature, and lighting surrounding the animals can be easily controlled which is not possible in humans. The use of animal models in experimental research is being done historically. In the early 1980s, scientists were neither aware nor sure about the appropriate toxicological assessment program for a new class of NCEs, biotechnology-derived pharmaceuticals or biopharmaceuticals (Hayes and Cavagnaro, 1992). It has been observed that toxicity evaluation in healthy rodent and non rodent species results in prediction of human risk in approximately $71 \%$ of instances (Olson et al., 2000). Use of laboratory animals in experiments is critical because complexity of human life cannot be duplicated in cell culture or in non living systems. For drug discovery research, it is essential to develop animal models which will mimic the human diseases. 
Till date, numerous animal models have been developed and used in discovery and safety evaluation of new drug molecules. In addition to this, these models have also played a significant role in understanding the mechanisms and etiology of various diseases. As models, scientists aim to produce artificially produce a condition in laboratory animals that may resemble the human equivalent of a medical disease or injury. The common use of animal models in drug discovery is to help in establishing nonclinical proof of concept as well as for demonstrating efficacy for a particular molecule under consideration. Besides the determination of markers for primary efficacy, animal models are also used to study endpoints that support target identification and to study pharmacodynamic effects (Sherry et al., 2012).

FDA and Critical-Path Institute launched Predictive Safety Testing Consortium (PSTC) to assess new biomarkers using animals for nephrotoxicity, hepatotoxicity, vascular injury, genotoxic and non-genotoxic carcinogenicity studies. More than 20 biomarkers were proposed for nephrotoxicity assessment to the FDA for qualification consideration in June 2007 (Burckart, 2008). The American Physiological Society (APS) has defined translational research as 'the transfer of knowledge gained from basic research to new and improved methods of preventing, diagnosing, or treating disease, as well as the transfer of clinical insights into hypotheses that can be tested and validated in the basic research laboratory (Hall, 2002).

Decisions on the choice of a relevant experimental model and the design, execution and evaluation of the experiments have to be made carefully. Both the economic and ethical aspects become important factors, when a potential therapy fails either in human or later trials (US FDA, 2004). Judicious use of laboratory animal is one way of reducing the high attrition rate (Bhogal and Balls, 2008). The significant inventions in the area of medicine have been possible only due to the use of animals (Pawlik, 1998). Laboratory animals produced by gene manipulation techniques fulfil much of the criteria for making them most useful for study of human diseases.

Genetic alterations in mouse/rat lead to functional changes predicting the correlation of pharmacologic effect in human. This review will provide an overview of the importance of in-vivo studies in translational research, its status, overview of national and international regulations, current methods of rodent model development, limitations and challenges of animal models and future perspective. According to Isselhard et al., 1986, a good animal model comprises of the following;

1. Animal model used should be representative of the human disease under investigation.

2. Availability of the animal model

3. It should be sufficient enough in size for sampling of biological specimens.

4. It should be easy to handle

5. Species and strains of that animal model should be available

6. Sufficient life span to undertake research
7. The animal model should be robust for the purpose of the study.

\section{Historical perspective of usage of laboratory animals in research}

Human beings have been using vertebrate animal species as models to study their physiological functions and anatomy since the inception of medicine (Staden and Herophilus, 1989). Domesticated rats (Rattus norvegicus) were the first rodent species to be used for scientific purposes and in the early years of the twentieth century they became a preferred system for biomedical research. In the year 1909, the first standard rat was developed called the Wistar Rat (Lindsey et al., 2006). Scientific breakthroughs especially the famous 'Koch's 'Postulate' in the field of microbiology lead to an increased use of animals. The principle stated that pathogenicity of a microorganism can be studied and validated after infecting healthy, susceptible animals (Van et al., 2001).

In 1980, John Gordon and Franck Ruddle developed the first transgenic mouse (Gordon and Ruddle, 1981). In 1988, the first gene knockout model was produced. In 2002, mouse became the second mammal, after humans, to have its whole genome sequenced. The use of animals in toxicity studies started way back in the decade of $1920 \mathrm{~J} \mathrm{~W}$ Trevan proposed $\mathrm{LD}_{50}$ test to determine the lethal dose of individual chemicals depending on the mortality of $50 \%$ of animals. John Draize developed the technique to test safety of any chemical for organs like eye and skin. Some of the traditional toxicity protocols date back about 50 years, and were developed at a time when knowledge of molecular biology and various signalling pathways in any animal was not known or unclear. A comprehensive evaluation of all these protocols is highly needed in the light of advancement of knowledge in genomics and proteomics, so that these protocols can be reformulated. Figure 1 illustrates the advantages of laboratory animals in research in a precise manner.

1. Elucidate mechanisms of drug action

2. Relate drug exposure to surrogate of functional outcome either efficacy for or safety

3. Helps to study mechanistic biomarker for drug as well for chemical

4. Reliable scientific approach for predictive research

5. Improves safety and refine targeting of early clinical studies

Fig. 1: Advantages of using laboratory animal as models in biomedical research.

American National Research Council Committee on Animal Models for Research and Aging, have classified animal models used in biomedical research into five groups as:

(1) Spontaneous models in which diseases occur spontaneously in animals as in humans, (2) disease mimicked using chemicals (3) genetically modified models by genetic manipulation (4) negative models, including animals resistant to a particular disease 
condition and (5) orphan models, including animal models with disease unknown to human counterparts (Canadian council of animal care, 2016). We will discuss few of the important animal models to study various diseases.

\section{Spontaneous animal models}

Animal models that have developed spontaneously over the period of time in the life span of particular animal. They mimic specific diseases of humans. Notable examples of these are the Gunn rat (for hereditary hyperbilirubinemia) and the BB Wistar rats (for type I diabetes). Heideman P in 2004 explained the strong basis for the study of genetic variation, and for using models that exhibit this feature.

\section{Inbred animals}

Commonly used inbred strains of laboratory mice like C57BL/6, DBA, BALB/c were purposefully produced by generations of brother-sister mating to create homogenous lines. The genome of one mouse strain C57BL/6J has been almost fully sequenced.

\section{Specific pathogen free animals}

SPF animals are special stock of animals that are kept in specific pathogen free facilities under rigorous monitoring system, which are subjected to sensitive and accurate diagnostic methods. The animals are repeatedly bred under controlled conditions to maintain their freedom from specific pathogens and the SPF designation itself is tested on a regular basis over an extended period of time. SPF animals are not disease free nor are they disease resistant. They may well carry other pathogens for which their health status has not been assessed. Apart from these, animal models are developed to undertake mechanistic studies. The most commonly used pharmacological model related to Alziermer's Disease is scopolamine-induced amnesia (Ebert and Kirch, 1998). Another way to develop model for Alziemer's disease is direct intracerebral injection of Ab peptides causes learning and memory deficits, as well as AD-like behavioural alterations (Sipos et al., 2007). Laboratory mice are the most common species explored as a model to study asthma. In principle, mice are sequentially sensitized to allergen with alum as an adjuvant via intraperitoneal injection and challenged to allergen through the airways (Zosky and Sly, 2007).

Ovalbumin derived from chicken egg is a widely preferred as an allergen as it induces robust, allergic inflammatory cascade in mice (Kumar et al., 2008). 7, 12 dimethylbenz $[a]$ anthracene (DMBA) and methylnitrosourea (MNU) induced mammary gland carcinogenesis models are routinely used for tumour studies. The 50 day old rat MNUinduced cancer model is popular because it typically produces $100 \%$ incidence of adenocarcinomas within 120-150 day of carcinogen treatment (Moon and Mehta, 1989). The diethyl nitrosamine (DEN) model induces lung adenocarcinomas following twice-weekly subcutaneous injections of $17.8 \mathrm{mg}$ $\mathrm{DEN} / \mathrm{kg}$ body weight (bw) starting at 7-8 wk of age and continuing for 20 Weeks (wk) (Moon et al., 1992). This treatment usually produces $90-100 \%$ tracheal tumors and 40-50\% lung tumors in treated male Syrian golden hamsters. Another group of animals used in biomedical research is an inbred strain developed after close brother sister mating over 20 generations. Animals from the same inbred strain are considered as genetically identical. Another group of animals used for research are the Congenic strains; they are developed through repeated backcrosses to an inbred background strain to select a unique marker over a minimum of 10 generations. Inbred strains used as a background strains for the production of Congenic strains are C57BL/6, $\mathrm{BALB} / \mathrm{c}$ and CD-1.

To study obesity, Zucker rat is a commonly used obese rat model. An autosomal recessive mutation in the fatty gene ( $f a$ ) leads to development of obesity in Zucker rat (Phillips et al. 1996). The $o b / o b$ mouse is a monogenic model of obesity and diabetes due to a lack of leptin production. It is the commonly used model for obesity and diabetes research. The $d b / d b$ mouse, resembles with $o b / o b$ mouse in many parameters and carries mutations in the leptin receptor (Hummel et al., 1966).Cotton rats are widely used to study infectious diseases because of their unique susceptibility towards human pathogens.

It is important to note that mice and rats often are not susceptible to human pathogens. Various types of animal models to study type 2 diabetes have been developed by approaches like spontaneous, using certain chemicals, dietary modifications, through surgical manipulations or combinations of these (Srinivasan and Ramarao, 2007).

Figure 2 explains the use of laboratory animals and endpoints of specific in-vivo study (Fig: 2)

\begin{tabular}{|c|c|}
\hline Purpose & Endpoints \\
\hline Basic research & $\begin{array}{l}>\text { Different biochemical and disease pathways in } \\
\text { any particular disease of interest are studied } \\
>\quad \text { To study genetic diseases }\end{array}$ \\
\hline Regulatory requirement & $\begin{array}{l}\text { These studies are mandatory from regulatory view } \\
>\quad \text { Toxicity studies } \\
>\text { Absorption, distribution, metabolism, excretion, } \\
\text { (ADME) } \\
>\text { Efficacy studies }\end{array}$ \\
\hline Teaching purpose & $\begin{array}{l}\text { Education and training of students by necropsy, } \\
\text { anatomy and basic physiological principles }\end{array}$ \\
\hline $\begin{array}{l}\text { Drug Discovery/Developing } \\
\text { therapeutic strategies }\end{array}$ & $\begin{array}{l}\text { Target identification through } \\
\text { Genomics/proteomics, or proteins in humans and } \\
\text { model organisms } \\
>\quad \text { Target validation (via gene knockout or gene } \\
\text { knockdown with RNAi or antisense compounds, } \\
\text { and/or by over expression of target genes) }\end{array}$ \\
\hline
\end{tabular}

Fig. 2: Animal models and their uses. 
Use of small laboratory animals in preclinical safety studies Objectives of any preclinical regulatory are;

(1)To find out the initial safe starting dose and dose escalation system for clinical use, (2) To obtain an idea about possible risk versus benefit ratio of test item in humans, (3) To find out potential target organs and probable reversibility of toxicity (4) To identify endpoints of study for clinical studies, (e) To identify patient inclusion/exclusion criteria (Stromberg et al., 1995). Success of any preclinical animal safety study primarily depends on preclinical study (1) Selection of the appropriate animal species, (2) availability of the target receptor (3) binding capacity of molecule with receptor (4) the metabolic and pharmacologic profile of the animal model used. Figure 3 depicts the primary usage of small laboratory animals in various studies.
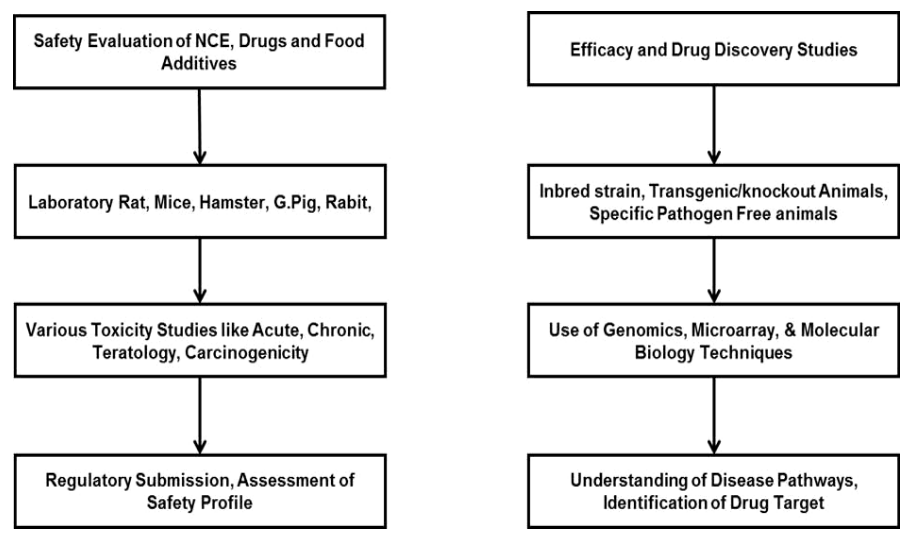

Fig. 3: Positioning of laboratory animals in research.

\section{Recent advances in model development}

Xenograft models, where human tumors are "cultivated" in immune-compromised mice have demonstrated fast and cheap solution for therapeutic testing. Such models are part of all standard drug development programmes and are a pre-requisite to clinical trials. For historical reasons these "artificial" models are preferred over Genetically Engineered Mouse Models (GEMMs), as they have been used for over 50 years (Newell et al., 2008). Primary goal of studies using xenograft models is to confirm that the "targeted" therapy under investigation hits the intended target that should be present in the tumor cell line used in the study. On the other hand, orthotopic models are labour intensive as they require surgical inoculation of tumor cells into the specific organ (liver, spleen) and the use of sophisticated imaging technologies and serum biomarkers to monitor the tumor take rate, tumor growth and effects of therapy on tumor progression. However, because in orthotopic models, the tumor is placed in its native environment (organ), studies performed in these models provide data with higher predictability (Cedo and Catharine, 2010). In orthotopic model, the tumor tissue is placed in the native environment of primary tissue. Xenograft models are relatively easy to perform; simple caliper measurement of tumor size provides insight regarding compound efficacy measured as inhibition of tumor growth. Islet transplantation for the treatment of type1 diabetes patients was achieved after completing proof-of- concept studies in islet allo-transplanted in rat model and then in a rhesus macaque model (Ballinger and Lacy, 1972; Ricordi et al., 1992; Scharp et al., 1990). Recently, use of animal models for imaging techniques such as PET and MRI are being done on higher scale to study drug delivery. Use of animal models for these imaging has significantly helped to increase the potency and minimize toxicity of drug molecule in humans. Back-translation of imaging techniques from humans to animals has emerged very significantly and yielded promising results. Many techniques have been directly developed in humans and now they those need to be validated in animal models (Johannson, 2009).Use of imaging techniques like Computerized Tomography Scan (CT scan), Positron Emission Transmission (PET scan), Magnetic Resonance Imaging (MRI) have significantly reduced the sample size required for any in-vivo study compared to a conventional histological approach where only group comparisons can be made. This is in accordance with the $3 \mathrm{Rs}$ in preclinical research: refinement, reduction and replacement (Flecknell, 2002).

Apart from above discussed models, Patient-derived xenograft (PDX) models are being used to study cancer biology. Tumor diversity is one of the major hurdles for cancer drug development (Tentler et al., 2012). These models are contributing significantly for screening of anticancer drugs as well as for development of biomarkers. These models are proving best for personalized treatment of various cancers in humans. Studies were conducted in the 1980s using PDX models which showed significant correlation between clinical response to cytotoxic drugs in adult patients with the lung cancer and in PDX models generated from these patients (Fiebig, 1985).Fragments of tumors removed directly from patients are implanted into immunodeficient mice, most of them in chemonaive condition, and generally retain the histological characteristics of the parental patient tumors. Number of studies revealed that PDX models preserve mutation profiles as well as the response patterns to targeted therapies (Fiebig et al., 2001; Uronis et al., 2012; Guerreschi et al., 2013). However there are some limitations of PDX models. It normally takes 4 to 8 months to develop a PDX model, many times cancer patients does not have this much time to wait. Another limitation is some PDX models show critical posttherapeutic tumour characteristics, such as residual disease and tumor relapse. Aprt from this stroma and tumour tissue comes from different biological sources that leads to poor interaction between them.

\section{Transgenic /knock out/ knock in animals Gene manipulation technique;}

It is important to note that many human diseases either do not exist in animals or are only developed by 'higher' mammals. This fact minimizes the option of animal models of human diseases, apart from this use of higher animals requires more money. Spontaneously developed animal models of these diseases do not exist (Pinkert, 2002). Earlier research of mouse genetics was based largely on spontaneous mutations that would arise in mouse breeding colonies (Alfred et al., 2012). Thereafter, 
researchers used genetic approaches used in radiation and chemical treatments to induce mutations. The advance in gene manipulation techniques have lead to the creation and use of genetically engineered laboratory mice and rats. These animal models are being used as powerful tools for cutting edge studies of human disease research including the drug discovery and mechanistic studies.

It has given scientists detailed insight about how genetic variations among humans can affect many aspects of disease risk and progression as well as about response to various treatments. Efforts of Martin Evans (Evans and Kaufman, 1981), Oliver Smithies (Smithies et al., 1985), and Mario Capecchi (Thomas et al., 1986) led to techniques of generating mouse models with gene-specific changes. This strategy is collectively known as gene targeting which ultimately lead to the generation of knockout mice.

Transgenic animals are only those that carry foreign DNA within their own genome or existing DNA altered, knock-ins or knock-outs in whom specific genes of interest are inserted or made inoperative while the more recently developed knock-downs animals in which silencing of genes is achieved by insertion of DNA-constructs coding for specific small interfering RNAs or by antisense technology (Ariane et al., 2009). The term 'transgenic' was coined in 1981 by Gordon and Ruddle (Gordon and Ruddle, 1981).The availability and use of knockout and transgenic mice are widespread, and it is now possible even to hire biotechnical companies to produce designer mice. The next generation of mice with temporal and/or tissue-specific control of particular genes is on its way and will soon replace the earlier models of knockouts and knock-ins (Emilie, 2004).

Examples of mice developed by gene manipulation technique are; FGF5 mice (fibroblast growth factor) knockout mice having long angora like hairs and p27 knockout mice, which is bigger than normal mice. Larger size of p27 mice is not because of obesity but because of the increase in the skeletal structure (Keiko et al., 1996). Effect of target blockade by new therapeutic drug molecules can be estimated in knockout mice model than in a wild-type mice in order to know the efficacy or adverse effects (Bussiere et al., 2009).At present, the most common approaches used for genetic manipulation are; DNA microinjection, retrovirusmediated gene transfer, and embryonic stem (ES) cell mediated gene transfer. Use of transgenic/knock out/knock in animals will help researchers in identifying new drug targets, in disease modelling and in future may help in replacing non human primates.

Transgenic animals are produced primarily through: (i) germline modifications of gametes; (ii) microinjection of DNA or gene constructs into zygotes; (iii) incorporating modified cells, including embryonic stem (ES) cells into later stage embryos. Approximately, 11,000 genes have been knocked out in mice, which accounts for roughly half of the mouse genome (Vogel, 2007; Sikorski and Peters, 1997). Researchers worldwide are rigorously exploiting approaches like gene targeting and gene trapping, to make a knockout mouse for all of the 25,000 mouse genes (Grimm, 2006). The major drawback of such gene manipulation techniques is that the same gene mutation can produce variable symptoms even in different mouse breeds (Ulatowski et al., 2004). One of the important uses of transgenic animals is to produce biologically active proteins which are used as bioreactors instead of traditional bacterial and cell culture-based systems. The use of animal transgenesis is an important contribution to drug development particularly for complex molecules. Transgenic animal models for human xeno transplantation remain a promising option for overcoming severe donor organ shortages. Researchers all over the world will continue to address the biological barriers that are yet to be removed (Lam, 2005; Yamada, 2005).Transgenic animals have been widely used for the study of basic and mechanistic research and to study physiological processes, but their use in safety evaluation studies is minimal. Researchers look forward that with the recent drafting of an Organisation for Economic Co-operation and Development (OECD) guideline for transgenic rodent mutation assay (Lamber et al., 2008), the transgenic mouse models in combination with the traditional 2-year cancer bioassay in rats (EC, 2006; Wells and Williams, 2009), and other advancements, there will be a more active use of transgenic animals for toxicity/safety evaluation studies and hence for the risk assessment programme.Tg26 HIVAN mouse model was the first transgenic model developed in 1991 to study Human Immuno Deficiency Virus (HIV) ( Rosential et al., 2009). Models like beta receptor knockout mouse and uncoupling protein (UCP1) knockout mouse to study antidiabetic molecules were also developed (Srinivasan and Ramarao, 2007; Henson and Timothy, 2006). Mouse models using transgenic technology were also developed to study angiogenesis, arterial stenosis, atherosclerosis and thrombosis (Snaith and Tornell, 2002). Atherosclerosis is one of the emerging diseases because of modern lifestyle. Researchers all over the world have developed several genetically modified and transgenic animal models that replicate human atherosclerosis. Genetically modified mice have been used widely used to study atherosclerosis, among them are LDL-r-KO mice (Bombo et al., 2013) and E-KO mice (Cleverley et al., 2013).

\section{CRISPR-CAS9 mediated genome engineering technique:}

CRISPER-CAS9 stands for Clustered regularly interspaced short Palindromic repeats and CAS9 is an RNAguided DNA endonuclease enzyme associatedwith the CRISPR. Techniques mentioned earlier for the production of genetically modified animals are complex and requires more time. Recently CRISPR-CAS9 mediated genome engineering technique is being used for the production of genetically modified laboratory animals. It allows production of knockout, knock-in or conditional knockout mice by direct pronuclear injection in embryos. Genetic modification can be performed in any strain for which pronuclear injection is possible, thus eliminating the need for ES cells and backcrossing. With the help of this techniques genes on the same chromosome can be mutated simultaneously, avoiding the need for double targeting of ES cells (Randall et al., 2014) 
Table 1 illustrates some of the animal models and methods to develop them.

Table 1: Animal models for important diseases and methodologies for effective model development.

\begin{tabular}{|c|c|c|c|c|c|}
\hline \multirow[b]{2}{*}{ Sr. no } & \multirow[b]{2}{*}{ Disease } & \multicolumn{2}{|c|}{ Methodology } & \multirow[b]{2}{*}{ Spontaneous } & \multirow[b]{2}{*}{ References } \\
\hline & & $\begin{array}{l}\text { Chemical } \\
\text { used }\end{array}$ & $\begin{array}{l}\text { Transgenic/kn } \\
\text { ock in/out } \\
\text { technique }\end{array}$ & & \\
\hline 1 & $\begin{array}{c}\text { Diabetes- Type } \\
2 \\
\end{array}$ & $\begin{array}{c}\text { Alloxan } \\
\text { Streptozotoc } \\
\text { in }\end{array}$ & NA & NA & $\begin{array}{l}\text { Vogel, 2008; } \\
\text { Ozturk et al, } \\
1996\end{array}$ \\
\hline 2 & $\begin{array}{c}\text { Diabetes- } \\
\text { Type } 2\end{array}$ & NA & NA & $\begin{array}{c}\text { Obese: } \\
\text { ob/ob mouse } \\
\mathrm{db} / \mathrm{db} \text { mouse } \\
\text { Non-obese: } \\
\text { Cohen } \\
\text { diabetic rat }\end{array}$ & $\begin{array}{l}\text { Srinivasan and } \\
\text { Ramarao, } 2007\end{array}$ \\
\hline 3 & Diabetes-Type 2 & NA & $\begin{array}{l}\text { Knockout } \\
\text { mouse }\end{array}$ & NA & $\begin{array}{l}\text { McIntosh and } \\
\text { Pederson, 1999; } \\
\text { McNeil, 1999; } \\
\text { Kadowaki, } 2000 .\end{array}$ \\
\hline 4 & $\begin{array}{c}\text { Sq Cell } \\
\text { Carcinoma of } \\
\text { skin }\end{array}$ & NA & Knock in & NA & $\begin{array}{l}\text { Caulin et al., } \\
2007\end{array}$ \\
\hline
\end{tabular}

\section{Uncertainty in predictability of certain animal models}

Certain toxic effects of drug molecule cannot be predicted by the classical animal model, which frequently leads to failure of drug candidates as a result of toxicity in clinical trials (Stevens, 2006). Different chemicals/molecules exhibit variable sensitivity in different species. Morphine shows strong emetic tendency in dogs, while it does not have this effect in rats, and its effect in humans is minimal (Ernst et al., 2009). Such species variation leads to questions about predictability of certain animal models. These are the alarming questions in a safety evaluation research. Similarly, mimicking of human disease in animal has showed some poor predictability. Inability to show correlation between some animal efficacy studies and human clinical outcomes is believed to be due to shortcomings in experimental design and conduct, as well as reporting results (Everitt, 2015).Federation of European Laboratory Animal Scientist Association (FELASA) working group has suggested key questionnaire (Smith et al., 2007). This questionnaire if scientifically well addressed may increase predictability of animal models. These questions are;

1. Are the aim and objective original, realistic and timely?
2. How will the results will add to the existing knowledge? How will they be used?

3. How is the work related to previous and ongoing work in the research group and elsewhere?

4. Choice of animal model and scientific method adopted

5. Experimental design

6. Competence of staff

7. Appropriate facilities

8. Reporting and communication of results

The animal model selected or developed should be justified based on the biochemical, pharmacological and clinical observations which are already available. Nature of pharmaceutical molecule and its physicochemical properties also affects the choice of the model. Specific aspects of study may require different models to study them; such as the selfadministration paradigm and conditioned place preference models (Panillio and Goldberg, 2007). Sometimes clinical trials fails even if conducted on large scale fails either because they are unable to detect uncommon findings or because the sample size of population was not representative of actual population (FDA CPI, 2004). Research in neuroscience has low predictability using animal models. Reasons for this could be, (1) inability to accurately assess clinical signs like dizziness, hallucinations, etc. in nonclinical species; and (2) differences in blood-brain transport between healthy nonclinical species and human subjects that have a disorder compromising the blood-brain barrier. Another area where toxicity prediction is lower is the hepato-biliary toxicity. Drug-induced liver injury has been noted to be a frequent cause of failure of clinical trials and post-approval withdrawal (U.S. Food and Drug Administration, FDA, 2009). It is important to note that safety evaluation of small molecule NCEs is highly predictive of parameters like hematologic, gastrointestinal, and cardiovascular toxicities while there is a lower predictability of cutaneous, neurological and hepatobiliary toxicities (Olson et al., 2000). Animal models of human disease may result in improved assessment of human relevance in some instances, primarily by helping to understand the mechanism of toxicity once a particular toxicity has been identified. It is to be believed that even the optimal use of animal models of disease in nonclinical testing will not result in a $100 \%$ predictability or understanding of toxicities that may be encountered in a clinical setting (Sherry et al., 2012). Malignancies, Alzheimer's disease (AD) or osteoarthritis are diseases of the elderly population and thus investigations of new drug candidates in young animals for these diseases can give misleading results (Bouchlaka et al., 2013). Animal models when carefully selected, designed and conducted are an important part of any translational drug development strategy. Their translational value can be further enhanced when combined with other translational tools such as quantitative systems pharmacology, biomarkers or experimental clinical trials (Tinneke et al., 2014). Troglitazone is drug molecule which was taken by over 1 million people with less than $1 \%$ suffering liver failure. However it was withdrawn because of the side effect of liver failure (U.S. Food and Drug Administration, FDA, 2009).It is important to note here 
that animal studies of Troglitazone failed to reproduce liver failure. A survey was conducted by Japanese Pharmaceutical Manufacturers Association in 1994 about 64 marketed drugs in Japan. Interestingly they found that 39/91 (43\%) clinical toxicities were not a predictive forecast from animal studies (Igarshi, 1994). In the history of drug development in the world, Thalidomide disaster proved one of the eye openers for regulators all over the world. Thalidomide was a drug used to counter vomiting tendency during pregnancy in women in the late 1950 and early 1960s. The children of some of these women were born without limbs, a condition known as phocomelia. The teratogenic effects like deformities in limb and other effects were attributed to thalidomide. Approximately 10 strains of rats, 15 strains of mice, 11 breeds of rabbits, 2 breeds of dogs, 3 strains of hamsters and 8 species of primates in which thalidomide has been tested revealed sporadic response (Schardein, 1976). The thalidomide episode led to the adoption of requirements for the systematic testing of pharmaceutical products for developmental toxicity prior to marketing. Rofecoxib is another drug withdrawn from market because less than $1 \%$ of people those took Rofecoxib experienced a heart attack or sudden stroke (Topo, 2004). Another striking example about variable predictability is GM mouse. Genetically modified mouse model having same mutations was developed to study cystic fibrosis of humans but the mice developed different symptom patterns as compared to humans (Ameen et al., 2000).Biotechnology-derived pharmaceuticals are the emerging area in pharmaceutical development. Principles of safety evaluation are not different than for NCEs but the practices have differed based on product attributes (Cavagnaro, 2002). The final drafting of agreement on the ICHS6 guideline "Preclinical Safety Evaluation of Biotechnology-derived Pharmaceuticals" was reached at the 4th ICH meeting in Brussels in July 1997. The guidance emphasizes that "toxicity testing in non-relevant species may be misleading and are discouraged." For biotech products, selection of the test species is usually accomplished by an in-vitro comparison of binding affinity or functional activity of the product in human and animal cells, followed by in-vivo demonstrations of pharmacological activity or cross reactivity in that test species (ICH S6, Joy Cavagnaro, 1997).

\section{Alternatives to rodent and non rodent studies}

Increased understanding about cellular, molecular and physiological mechanisms has lead to precise early understanding of disease state. Based on these understandings, we can now study in-vivo and in-vitro safety biomarkers at very early stage. Such biomarkers can often serve as the basis for earlier humane endpoints to avoid or reduce the duration and severity of pain in animal studies. This entire approach has subjected scientists to think of alternatives for in-vivo studies using animal models. Invitro approach has become more popular in recent time. It includes use of sub-cellular fractions, tissue-slices, organs perfused using certain fixatives and cell cultures including human tissue culture for prediction of toxicity testing and for mechanistic studies. Invitro approaches are routinely used for preliminary screening of potential drug molecules as well for chemicals to evaluate their safety/toxicity and efficacy (Shay and Wright, 2000; Steinhoff et al., 2000).Use of mathematical and computer modelling like molecular modelling is proving very helpful for drug discovery, precise development of drug molecule, structure-activity relationship of a drug versus the biological activity of a drug. Apart from this, physiologically based pharmacokinetic modelling (prediction of disposition of xenobiotics and their metabolites by integrating species-specific physiological parameters and specified computer programs to study anatomy, physiology and other processes for education and training purposes are now more popular (ICMR, guidance document, Use of animals in scientific research, 2000). Recent advances in human genome sequencing project and bioinformatics has established itself as an essential tool in target identification. The in-silico analysis of gene expression and gene function are now an integral part of it facilitating the selection of the most relevant targets to study particular disease (Georg, 2001).Such software programs helps to make a new drugs for the specific binding site and then in final stage animal testing is done for confirmatory results (Vedani, 1991).Lower vertebrates can be an good option because of the genetic similarities with higher vertebrates including mammals. Moreover, there are less ethical problems involved in the experimental use of lower vertebrates (Doke, 2015). Nearly $75 \%$ of the genes involved in human diseases are believed to have a functional homolog in the Drosophila melanogaster (Reiter et al. 2001; Wilson-Sanders, 2011). C. elegans is also is being used to study as a alternate model to study various neurological disorders like Huntington's disease, Parkinson's disease and Alzheimer's disease (Driscoll and Gerstbrein, 2003). Apart from this, these are also being used to study various immune disorders as well as to study cancer and diabetes (Faber et al., 1999; Link et al., 2001). Most recent technologies like the in-vitro whole embryo culture test and zebrafish have been used to study the mechanism of action of a drug molecule.

To obtain an insight into mammalian physiology advanced molecular techniques and use of an alternative test system like zebrafish are becoming more popular. Recent advances in gene expression techniques like real time PCR, microarray, analysis of SNP and omics technologies has made it possible to minimize use of laboratory animals. Zebrafish can be a good surrogate animal model to study cardiovascular toxicity (Zon and Peterson, 2005). Amphibian models can be used effectively for developmental toxicity studies (Song et al. 2003). Many prokaryotic organisms and eukaryotic cell-based systems, using bacteria (e.g., Escherichia coli) and yeast (e.g., Saccharomyces cerevisiae) have achieved milestones in basic research. Studies in $E$. coli have greatly contributed in the field of molecular biology, recombinant DNA technology and genetic engineering.

\section{Animal ethics issues}

In experiments involving laboratory animals, they are exposed to various invasive procedures, which includes surgeries, traumatic injuries, burns, force-feeding, bleeding, biopsies, food, 
water, and micro as well as macro environmental change, sedation, prolonged restraint, behavioural manipulations, viral and bacterial infections, and exposure to toxic drugs and chemicals. With the introduction of the concept of 3Rs (Replacement, Reduction, Refinement) and humane treatment in experimentation involving animals (Russell and Burch, 1959), enormous pressure is being mounted to minimize the usage of animals in all sort of experiments. The definitions of famous $3 r$ concepts are;

Refinement: Decrease in the incidence of severity of inhumane procedures applied to those animals which are used.

Reduction: Reduction in the number of animals used to get information of given amount and precision.

Replacement: Substitution of conscious living higher animals with insentient material

Following are the national and international guidelines/regulations which are to be followed before undertaking any in-vivo study;

1. PCA Act- 1960 (amended in 1982)

2. Laboratory animal ethics and technology, Central Drug Research Institute, Lucknow - 1991

3. Breeding and Experiments on Animals (Control and Supervision) Rules (CPCSEA) Dec.1998, amended in Feb.2001 \& Jan. 2006

4. INSA Guidelines for Care and Use of Animals in Scientific research- 1992 (revised in 2000)

5. ICMR's Guidelines for use of Laboratory Animals in Medical Research -2001

6. ICMR's Guidance document on Humane Care and Use of Laboratory Animals-2006

7. Animal Welfare Act (2011,Draft )

8. Good Laboratory Practice (GLP)

In-vivo experiments are must, however they should be performed with utmost scientific care and for legitimate purposes, every reasonable effort should be made to minimise pain or discomfort to animals undergoing experimentation. The non-human animals have a right to enjoy these welfare measures. These goals are highly achievable simply by two major approaches; husbandry conditions, which includes the effect of space, diet, social isolation and environmental conditions including noise, light and species wise housing of animals. The second one is the scientific procedures involved in experimental research like handling, oral dosing, injections, withdrawal of body fluids, withdrawal of food, etc.

\section{CHALLENGES}

Animal models of majority human diseases mimic only certain aspects of disease and do not fully represent the pathophysiology of the human disease state. Studies of penicillin on laboratory animals showed that penicillin was ineffective at treating infected rabbits (and was actually toxic to guinea pigs), thereafter it proved safe and effective for treating bacterial infections in most humans. Even data collected from experiments on aspirin could not be accurately extrapolated from animal studies to humans, as it causes birth defects in mice and rats, but is harmless to the human embryo. According to Dr. Richard Klausner scientists have cured cancer in mice for decades but we failed to cure in humans (Cimons, 1998). Potential drugs are often required to be tested in at least two animal species in preclinical trials before moving on to human clinical trials (Brewer, 2007 ), however only around $5 \%$ of drugs that show potential in animal studies ever get licensed for human use (Waters, 2011). Even with genetic engineering, animals are still proving to be poor models for humans. One reason why animal experiments often do not translate into replications in human trials or into cancer chemoprevention is that many animal experiments are poorly designed conducted and analyzed. Another possible contribution to failure to replicate the results of animal research in humans is that reviews and summaries of evidence from animal research are methodologically inadequate (Bracken, 1992). Several limitations of xenograft models have been recognized. Transplant models do not replicate interactions of tumor mass and stroma, either because tumor cells are not implanted at their native site or because human cells may fail to respond to signals derived from the mouse stroma (Latifa and Erwin, 2013). For many diseases like mood disorders, multiple sclerosis, asthma, and Parkinson's disease, the pathogenesis is multifactorial and often poorly understood. A potential problem with safety assessment is the condition that the disease itself or the protocol followed to induce the disease, results in confounding effects that are not related to the test article. Unavailability of historical controls could hamper the interpretation of results (Peter et al., 2015). Validation of animal model is another important challenge. An animal model is assumed to be valid, if it "resembles the human condition in its etiology, pathophysiology, symptomatology and response to therapeutic interventions" (Van and De, 2006). Robust initiatives have been launched to encourage the use of more accurate animal models in both industrial and academic research. Regulatory authorities from Europe and US have released guidelines which throws light on the key characteristics of an approved animal model. These guidelines are intended for use by those seeking approval or a licence for drugs or biological products. New stringent regulations pertaining to the animal welfare are becoming crucial during the development and utilization of GM/Transgenic animals (Sauer et al., 2006).Newer trends enlisted in Figure 4 are putting more challenges for in-vivo approaches.

1. Nanomedicine
2. Gene therapy
3. Silencing/siRNA
4. Peptides
5. Monoclonal antibodies
6. Stem cell therapy
7. GM based food supplements

Fig. 4: Current trends in therapeutics research. 


\section{FUTURE PERSPECTIVES}

The ultimate goal of experimental research using animal models is to get solution for therapeutic and prophylactic treatment of any disease as well as to develop new methods and approaches for diagnostics (Isselhard, 1986). Transgenic and knock out models have become frontrunners of choice in drug research, for validating the cellular and molecular mechanisms of disease, the creation of novel therapies, and the redefining of existing therapeutic strategies. Thus, the role of animal models should be not only in drug discovery and development research but also in training, educating the researchers/students with latest techniques to develop better understanding about diseases and their possible cure. It's clear that to develop more precise and predictive animal models used in experimentation we will require multidisciplinary approach which should involve scientists from clinical and basic sciences right from the beginning. So that we can identify common hurdles and pathways for improving model systems for the evaluation of therapeutic efficacy and toxicity in areas of biomedical as well drug research. While developing or selecting model for particular study, one has to keep in mind the concept of the model and its background from genomic and physiological aspects with respect to the molecule under consideration. Apart from this, the availability of target as well as intended use and target population are also key factors. There are certain hard realities of in-vivo research wherein mammals and even transgenic animals are being used. Laboratory mice have now become the widely used species in drug research. It is important to understand that at least 67 known discrepancies do exist in immunological functions between mice and humans. It is important to note that both these species diverged between 65 and 75 million years ago (Mestas and Hughes, 2004). When marmoset was used as model for Parkinson's disease, a specific chemical, was injected into the brains of marmosets, which developed symptoms such as tremor and movement difficulties in them, however in addition to this, other symptoms like head-twisting and body rotation do developed (Schober, 2004). It is also interesting to note that healthy marmosets start sudden and gradual improvement over a period of time; on the contrary the onset and progression of Parkinson's disease in humans is gradual, of unknown etiology without any spontaneous trend of recovery. Since several years research on AIDS is being carried out using a virus similar to humans but not the same as the human virus. Such vaccines have prevented infection in these primates but failed to protect humans: at least 85 candidate vaccines have been tested in 197 clinical trials (Bailey, 2008) but none has been effective (Buckland, 2008).

\section{CONCLUDING REMARKS}

Despite of some physiological and immunological differences between mice and humans (Mestas and Hughes, 2004), genomic sequencing has now indicated that of $\sim 30,000$ genes in both mice and humans only 300 (i.e., 1\%) are unique to either species (Waterston and Lindblad, 2002). Current animal models are helpful to answer many questions and discovery of new molecules but at the same time drug résistance, animal ethics issues and higher costs and development or selection of proper animal remains a challenge in the light of newer areas like nanomedicine, biopharmaceuticals, and herbal medicine. It is obvious that laboratory animal systems as a model are necessary for predictive research. Intended use of drug molecule, its proposed route and target population are the key factor for planning in-vivo experiments. To invent promising therapeutic strategies it is indeed required to improve the understanding of the disease and derive better therapeutic strategies for diseases like cancer with more precise approach using small laboratory animals. The challenges faced while using animal models for human disease mimicking are because of the metabolic, anatomic and cellular differences between humans and other laboratory animals. Importantly, another reasons are; researchers often use incorrect statistical methods, adopt an arbitrary methodology and reluctant to publish negative results. Key issue in In-vivo research is validation of models. A significant no of drug molecules fail in clinical trials because the model was biologically invalid. Genetic manipulation techniques have made possible to manipulate genes of interest of rodents and other species to get greater insights into human disease pathogenesis. Particularly, variations in gene expression and/or protein structure/function are now considered as the root causes of disease. Over the period of hundred years, approximately all medical inventions in human and animal health are the result of the research conducted using animals. The use of animals in research has now become an integral part of drug discovery and development programme. Sophisticated and effective methods for diagnosing and treating diseases affecting both humans and animals are the result of animal research. Various disease processes and their pathogenesis are understood only by animal research. However reality is that, still we are far from generating ideal animal models for most human disease states.

Even model systems with more phylogenetic similarity to humans, like primate models, fail to predict what happens in humans. Nucleotide difference between chimpanzees and humans is of only $1-2 \%$, however this minor difference results in variations/alterations of around $20 \%$, in terms of protein expression (Glazko et al., 2005), and representing a marked phenotypic difference between the species use of animal models in translational research is unavoidable. Selecting proper animal system and development of animal model that mimics the human disease has to be done carefully. Through understanding of pathophysiology of human disease, proposed mechanistic studies, scientific planning and execution of experiments, data interpretation and selection of relevant species will minimize the errors in results.

\section{CONFLICT OF INTEREST}

The authors declare that there is no conflict of interest amongst them. 


\section{REFERENCS}

Alabaster V. The in vivo Pharmacology Training Group. The fall and rise of in vivo pharmacology. Trends in Pharma. Sci., 2002; 23:13-18

Alfred D, Michael PM, Nancy A. Lee, and James J. Lee. The Construction of Transgenic and Gene Knockout/Knockin Mouse Models of Human Disease. Transgenic Res. 2012; 21(2): 327-349.

Ameen N, Alexis J \& Salas P. Cellular localization of the cystic fibrosis transmembrane conductance regulator in mouse intestinal tract. Histochemistry and Cell Biology, 2000; 114:69-75

Anonymous, 2013. Committee for Medicinal Products for Human Use (CHMP). Guideline on Strategies to Identify and Mitigate Risks for First-in-human Clinical Trials with Investigational Medicinal Products. London, UK. Discov. Today 10, 139-147

Anonymous. 2006. REACH Regulation (EC) No. 1907/2006 of the European Parliament and of the Council REACH. Official Journal of the European Union L 396, 2006:01-849.

Ariane K, Daniel B , Mario E, Barbara G, Marlies H, Frank H, Manfred L, Rainer N, Michael O, Kurt R, Bernd S, Andrea S and Andreas L. Implementation and Enforcement of the 3Rs Principle in the Field of Transgenic Animals used for Scientific Purposes Report and Recommendations of the BfR Expert Workshop, May 18-20, 2009, Berlin, Germany http://www.fda.gov/downloads/Drugs/GuidanceComplianceRegulatoryInf ormation/Guidances/UCM399217.pdf (Accessed 12 Dec 2015).

Bailey J. An assessment of the role of chimpanzees in AIDS vaccines research. ATLA 2008; 36:381-428

Ballinger, WF, Lacy PE. Transplantation of intact pancreatic islets in rats. Surgery. 1972; 72,175-186.

Bhogal N, Balls M. Translation of new technologies: from basic research to drug discovery and development. Current Drug Discovery Technologies 2008; 5:250-262.

Blyth DI, Pedrick MS, Savage TJ, Hessel EM, Fattah D. Lung inflammation and epithelial changes in a murine model of atopic asthma. Am. J. Respir. Cell Mol. Biol. 1996; 14:425-438

Bombo RP, Afonso MS, Machado RM, Lavrador MS, Nunes VS, Quintão ER, Koike M, Catanozi S, Lin CJ, Nakandakare ER. Dietary phytosterol does not accumulate in the arterial wall and prevents atherosclerosis of LDLr-KO mice. Atherosclerosis. 2013; 231:442-447

Bouchlaka MN, Sckisel GD, Chen M, Mirsoian A, Zamora AE, Maverakis E, Wilkins DE, Alderson KL, Hsiao HH, Weiss JM. Aging predisposes to acute inflammatory induced pathology after tumor immunotherapy. J.Exp. Med., 2013; 210 :(11)2223-2237.

Bracken M. Why animal studies are often poor predictors of human reactions to exposure. J R Soc Med. 2008; 101: 120-22.

Brewer T. Trials and Errors: Drug testing raises ethical - and efficacy - issues. Best Friends Magazine. 2007

Buckland G. 2008. Replacing primates in the search for an AIDS vaccine. In: Replacing Primates in Medical Research: An expert report by the Dr Hadwen Trust, FRAME and Advocates for Animals. Available

http://www.dierproeveninformatie.nl/downloads/Replacing\%20primates\% 20in\%20medical\%20research.pdf (Accessed on 12 Dec 2015)

Burckart GJ. Qualification of biomarkers for drug development in organ transplantation. Am. J. Transplant. 2008; 8:267-270

Bussiere JL, Martin P, Horner M, Couch J, Flaherty M, Andrews L, Beyer J, Horvath C. Alternative strategies for toxicity testing of species-specific biopharmaceuticals. Int J Tox 2009; 28:230-53.

Canadian Council on Animal Care 1510-130 Albert Street Ottawa ON CANADA K1P 5G4. Available at: http://www.ccac.ca/Documents/Standards/Guidelines/Farm_Animals.pdf (Accessed on 10 Jan 2016)

Caulin C, Nguyen T, Lang GA, Goepfert TM, Brinkley BR, Cai W-W, Lozano G, Roop DR. An inducible mouse model for skin cancer reveals distinct roles for gain- and loss-of-function p53 mutations. J Clin Invest 2007; 117: 1893-1901.

Cavagnaro J, Lima BS. Regulatory acceptance of animal models of disease to support clinical trials of medicines and advanced therapy medicinal products. European Journal of Pharmacology, 759 (2015) 51-62 Cavagnaro JA. ICHS6 Preclinical Safety Evaluation of Biotechnology-Derived Pharmaceuticals, Nature Reviews Drug Discovery , 2002; 1:469-475

Cavagnaro, JA. Preclinical safety evaluation of biotechnologyderived pharmaceuticals. Nat. Rev. Drug Discov. 2002; 1:469-475

Cedo MB, Catharine JA. Models of Hepatocellular Carcinoma and Biomarker Strategy. Cancers, 2010; 2:1441-1452

Cheon DJ, Orsulic S. Mouse models of cancer. Annu. Rev. Pathol. 2011; 6: 95-119

Cimons M, Getlin J, Maugh T. Cancer drugs face long road from mice to men. Los Angeles Times, 1998; A1

C-L Hsieh, Z Xie, Z-Y Liu1, J E Green1, W D Martin, M W

Datta. F Yeung,D Pan and L W K Chung, A luciferase transgenic mouse model: visualization of prostate development and its androgen responsiveness in live animals. Journal of Molecular Endocrinology (2005) 35, 293-304

Cleverley K, Du X, Premecz S, Le K, Zeglinski M, Nicholson T, Goh CY, Lu Y, Anderson HD, Moghadasian MH. The effects of fish oil consumption on cardiovascular remodeling in ApoE deficient mice. Can J Physiol Pharmacol, 2013; 91:960-965

Driscoll M, Gerstbrein B. Dying for a cause: Invertebrate genetics takes on human neurodegeneration. Nat. ReV. Genet. 2003; 4(3):181-194.

Ebert U, Kirch W. Scopolamine models of dementia: electroencephalogram findings and cognitive performance. Eur J Clin Invest 1998; 28:944-949.

Emilie FR. Thinking outside the Mouse Box: The Importance of Comparative Laboratory Animal Models in Research. ILAR J, 2004; 45(1): 1-3.

Epstein MM. Do mouse models of allergic asthma mimic clinical disease. Int. Arch. Allergy Immunol, 2004; 133:84-100

Ernst S, Boyer S, Platz S. In Principles of Translational Science in Medicine. Edited by Wehling M. Cambridge University Press. Pharmaceutical toxicology, 2009; 299-326

Evans MJ, Kaufman MH. Establishment in culture of pluripotential cells from mouse embryos. Nature, 1981; 292(5819):154156.

Everitt JI. The future of preclinical animal models in pharmaceutical discovery and development: a need to bring in cerbro to the in vivo discussions. Toxicol. Pathol., 2015; 43:70-55.

Faber PW, Alter JR, MacDonald ME, Hart AC ,Polyglutaminemediated dysfunction and apoptotic death of a Caenorhabditis elegans sensory neuron.Proc. Natl. Acad. Sci., 1999; 96:179-184

Fiebig HH, Burger AM: Human Tumor Xenografts and Explants. In Teicher BA ed, Tumor models in Cancer Research. 2001, 113-137

Fiebig HH, Neumann HA, Henss H, Koch H, Kaiser D, Arnold H. Development of three human small cell lung cancer models in nude mice. Recent Results Cancer Res 1985;97:77-86.

Flecknell P. Replacement, reduction and refinement, ALTEX, $2002 ; 19: 73-78$

Georg CT, Angelo R. In silico research in drug discovery. TRENDS in Pharmacological Sciences, 2001(22):23-26

Giridharan NV, Kumar V, Muthuswamy V. ICMR guidance document Use of animals in scientific research, New Delhi, India; 2000

Glazko GV, Nei VM, Makal OW. Eighty percent of proteins are different between humans and chimpanzees. Gene, 2005; 346:215-219

Gordon JW, Ruddle FH. Integration and stable germ line transmission of genes injected into mouse pronuclei. Science, 1981 214:1244-1246

Grimm DA. Mouse for every gene. Science 2006; 312:1862-

1866

Guerreschi P, Scalbert C, Qassemyar A, Kluza J, Ravasi L, Huglo D, Martinot-Duquennoy V, Formstecher P, Marchetti P, Mortier L. Patient-derived tumor xenograft model to guide the use of BRAF inhibitors in metastatic melanoma. Melanoma Res. $2013 \mathrm{Jul} 10$.

Hall JE. The promise of translational physiology. Am. J. Physiol, 2002; 283:235-236 
Hayes TJ, Cavagnaro JA. Progress and challenges in the preclinical safety assessment of cytokines. Toxicol. Lett., 1992; (64/65): 291-297.

Heideman PD. Top-down approaches to the study of natural variation in complex physiological pathways using the white-footed mouse (Peromyscus leucopus) as a model. ILAR Journal, 2004; 45:4-13.

Henson MS. Timothy DO. Feline Models of type 2 Diabetes Mellitus. ILAR Journal, 2006; 47(3):234-42.

Hummel KP, Dickie MM, Coleman DL. Diabetes, a new mutation in the mouse. Science 1966; 153:1127-1128.

Igarashi $\mathrm{T}$. The duration of toxicity studies required to support repeated dosing in clinical investigation - A toxicologists opinion. In CMR Workshop: The Timing of Toxicological Studies to Support Clinical Trials Edited by: Parkinson CNM, Lumley C, Walker SR.Boston/UK: Kluwer; 1994:67-74.

Isselhard WH, Kushe H, McKneally M, Mulder DS, Spitzer WO, McPeek B. Principles and Practice of research: Strategies for Surgical Investigators 3rd Edition. New York: Springer-verlag. J. Animal experimentation, 1998:419-434

Ito T, Ando H, Suzuki T, Ogura T, Hotta K, Imamura Y, Yamag uchi Y, Handa H. Identification of a primary target of thalidomide teratogenicity. Science, 2010;327:1345-1350

Johannson L: Translational imaging research. 2009. In Principles in Translational Science in Medicine. Edited by Wehling M. Cambridge University Press, 240-250

John J. Tentler, Aik Choon Tan, Colin D. Weekes, Antonio Jimeno, Stephen Leong, Todd M. Pitts, John J. Arcaroli, Wells A. Messersmith and S. Gail Eckhardt (2012). Patient-derived tumour xenografts as models for oncology drug development. Nat. Rev. Clin. Oncol. 9, 338-350

Kadowaki T. Insights in to insulin resistance and type 2diabetes from knockout mouse models. J Clin Invest, 2000; 106:459-65

Keiko Nakayama,Noriko Ishida, Michiko Shirane, Akira Inomata,Tomoaki Inoue,Nobuyuki Shishido, Ikuo Horii,Dennis Y. Loh, and Kei-ichi Nakayama.Mice Lacking p27Kip1 Display Increased Body Size, Multiple Organ Hyperplasia, Retinal Dysplasia, and Pituitary Tumors, Cell, Vol. 85, 707-720, May 31, 1996

Kinross KM, Montgomery KG, Kleinschmidt M, Waring P, Ivetac I, Tikoo A, Saad M, Hare L, Roh V, Mantamadiotis T. An activating Pik3ca mutation coupled with Pten loss is sufficient to initiate ovarian tumorigenesis in mice. J Clin Invest, 2012; 122:553-557.

Kumar RK, Herbert C, Foster PS. The "classical" ovalbumin challenge model of asthma in mice. Curr Drug Targets, 2008; 9:485-94

Lam TT. The effect of soluble complement receptor type 1 on acute humoral xenograft rejection in hDAF-transgenic pig-toprimate life supporting kidney xenografts. Xenotransplantation, 2005; 12:20-29

Lambert IB, Singer TM, Boucher SE, Douglas GR. Detailed review paper on transgenic rodent mutation assays. Mutat Res., 2005; 590(1-3):1-280.

Latifa B, Erwin F. Wagner.,Mouse models for liver cancer. Molecular Oncology, 2013; 7:206-223

Lindsey JR, Baker HJ, Suckow MA, Weisbroth SH, Franklin CL. 2006. Historical foundations. In The Laboratory Rat (Eds.) Elsevier: Amsterdam, The Netherlands.

Link CD, Johnson CJ, Fonte, Paupard VM, Hall DH, Styren S, Mathis CA, Klunk WE.Visualization of fibrillar amyloid deposits in living, transgenic Caenorhabditis elegans animals using the sensitive amyloid dye X-34.Neurobiol. Aging. 2001; 22:217-226

Mahajan R, Gupta K. Food and drug administration's FDA critical path initiative and innovations in drug development paradigm: Challenges, progress, and controversies. J Pharm Bioallied Sci. 2010; 2(4): 307-313.

McIntosh CHS, Pederson RA. Non insulin dependent animalmodels of diabetes mellitus. In: McNeil JH, editor. Experimental models of diabetes. Florida, USA: CRC Press LLC; 1999; 337-98

McNeil JH. Experimental models of diabetes. Florida, USA:CRC Press LLC; 1999

Mestas J, Hughes CC. Of mice and not men: differences between mouse and human immunology. Journal of Immunology, 2004;
172:2731-2738.

Moon RC, Mehta RG. Chemoprevention of experimental carcinogenesis in animals. Prev Med 1989; 18:576-591.

Moon RC, Rao KVN, Detrisac CJ, Kelloff GJ. Hamster lung cancer model of carcinogenesis and chemoprevention. Adv Exp Med Biol 1992; 320:55-61

N. Pujol, S. Cypowyj, K. Ziegler, A. Millet, A. Astrain, A. Goncharov, Y. Jin, A.D. Chisholm, J.J. Ewbank,Distinct innate immune responses to infection and wounding in the $\mathrm{C}$. elegans epidermis.Curr. Biol., 2008; 18:481-489

Newell P., Villanueva A, Friedman SL, Koike K, Llovet JM. Experimental models of hepatocellular carcinoma. J. Hepatol, 2008; 48:858-879.

Olson H, Betton G, Robinson D, Thomas K, Monro A, Kolaja G, Lilly P, Sanders J, Sipes G, Bracken W, Dorato M, Van DK, Smith P, Berger B, Heller A. Concordance of the toxicity of pharmaceuticals in humans and in animals. Reg Tox Pharm, 2000; 32:56-67

Ozturk Y, Atlan VM, Yildizoglu-Ari N. Effects of experimental diabetes and insulin on smooth muscle functions .Pharmacol Rev, 1996; 48:69-112

Panillio L, Goldberg SR. Self-administration of drugs in animals and humans as a model and an investigative tool. Addiction, 2007;102:1863-1870

Pawlik WW. The significance of animals in biomedical research.]. Znaczenie zwierzat w badaniach biomedycznych. Folia Medica Cracoviensia, 1198; 39:175-182

Peter JK, Melanie LG, Henk JS. The safety, efficacy and regulatory triangle in drug development: Impact for animal models and the use of animals European Journal of Pharmacology. 2015; 759:03-13

Phillips MS, Liu Q, Hammond HA, Dugan V, Hey PJ, Caskey CJ. Leptin receptor missense mutation in the fatty Zucker rat. Nat Genet, 1996; 13: 18-9

Pinkert, C.A. Introduction to transgenic animal technology. In Transgenic Animal Technology: A Laboratory Handbook (2nd ed.) 2002 $<1>3-12$, Academic Press

Reiter LT, Potocki L, Chien S, Gribskov M, Bier E. A systematic analysis of human disease-associated gene sequences in Drosophila melanogaster. Genome Res., 2001; 11:1114-1125

Rerup CC. Dugs producing diabetes through damage of the insulin secreting cells. Pharmacol Rev, 1970; 22:485-518

Ricordi C,Tzakis AG, Carroll PB, Zeng YJ, Rilo HL, Alejandro R, Shapiro A, Fung JJ, Demetris AJ, Mintz DH. Human islet isolation and transplantation in 22 consecutive cases.Transplantation, 1992; 53:407414.

Rosential P, Gharavi A, Agati VD, Klotman P. Transgenic and Infectious Animal Models of HIV-Associated Nephropathy. J Am Soc Nephrol, 2009; 20:2296-2304

Sams-Dodd F. Target-based drug discovery: is something wrong? Drug Discov. Today, 2005; 10:139-147

Sauer UG, Kolar R, Rusche B. The use of transgenic animals in biomedical research in Germany. Part 2: Ethical evaluation of the use of transgenic animals in biomedical research and perspectives for the changeover in research to research animal-free methods] [German]. ALTEX: Alternatives to Animal Experimentation, 2006; 23:03-16

Schardein J. 1976. Drugs as Teratogens, CRC Press

Scharp W, Lacy PE, Santiago JV, McCullough CS, Weide LG, Falqui L, Marchetti, Gingerich RL, Jaffe AS ,Cryer PE. Insulin independence after islet transplantation into type1 diabetic patient. Diabetes, 1990; 39:515-518

Scharp W, Murphy JJ, Newton WT, Ballinger WF, Lacy PE. Transplantation of islets of Langerhans in diabetic rhesus monkeys. Surgery, 1975; 77:100-105.

Schober A . Classic toxin-induced animal models of Parkinson's disease: 6-OHDA and MPTP. Cell and Tissue Research, 2004; 318:215224

Shay JW, Wright WE. The use of telomerized cells for tissue engineering. Nat. Biotech., 2000; 18:22-23

Sherry JM, Chandikumar S. Elangbam, SB, Evan J, Allison V, Tanja Z, Laura C. Use of Animal Models of Human Disease for 
Nonclinical Safety Assessment of Novel Pharmaceuticals,Toxicologic Pathology, 2012; 00:01-11,

Sikorski R, Peters R. Transgenics on the internet. Nature Biotech, 1997;15:289.

Sipos E, Kurunczi A, Kasza A, Horváth J, Felszeghy K, Laroche S. Beta-amyloid pathology in the entorhinal cortex of rats induces memory deficits: implications for Alzheimer's disease.Neuroscience, 2007; 147: 28-36.

Smith JA, van den Broek FAR, Canto' Martorell J ,Hackbarth $\mathrm{H}$, Ruksenas $\mathrm{O}$, Zeller W, Principles and practice in ethical review of animal experiments across Europe: summary of the report of a FELASA working group on ethical evaluation of animal experiments, FELASA Working Group on Ethical Evaluation of Animal Experiments, 2007; 41(2):143-160

Smithies O, Gregg RG, Boggs SS, Koralewski MA, Kucherlapati RS. Insertion of DNA sequences into the human chromosomal beta-globin locus by homologous recombination. Nature, $1985 ; 317: 230-234$

Snaith MR, Tornell J. The use of transgenic systems in pharmaceutical research. Briefings in Functional Genomics and Proteomics, 2002; 1(2):119-30.

Sonali KD, Shashikant CD. Alternatives to animal testing: A review, Saudi Pharmaceutical Journal, 2015; 23:223-229

Song MO, Fort DJ, McLaughlin DL, Rogers RL, Thomas JH, Buzzard BO, Noll AM, Myers NK. Evaluation of Xenopus tropicalis as an alternative test organism for frog embryo teratogenesis assaysXenopus (FETAX). Drug Chem. Toxicol, 2003; 26(3):177-189

Srinivasan K, Ramarao P. Animal models in type 2 diabetes research: An overview; Indian J Med Res, 2007; 125:451-472

Srinivasan KR. Animal models in type 2 diabetes research: an overview. Indian J Med Res., 2007; 125:451-72.

Staden V, Herophilus H. 1989. The Art of Medicine in Early Alexandria; Cambridge, Cambridge, UK: University Press.

Steinhoff G, Stock U, Karim N, Mertschin H, Timke A, Meliss $\mathrm{RR}$, Bader A. Tissue engineering of pulmonary heart valves on allogenic acellular matrix conduits in vivorestoration of valve tissue. Circulation, $2000 ; 102: 50-55$

Stevens JL. Future of toxicology mechanisms of toxicity and drug safety: where do we go from here? Chem Res Toxicol., 2006; 19:1393-1401

Stromberg K, Chapekar MS, Goldman BA, Chambers WA, and Cavagnaro JA. Regulatory concerns in the development of topical recombinant ophthalmic and cutaneous wound healing biologics. Wound Rep. Reg., 1995; 2:155-164

Thomas KR, Folger KR, Capecchi MR. High frequency targeting of genes to specific sites in the mammalian genome. Cell., 1986; 44:419-428.

Tinneke D, ThomasStöhr, Maarten VR, Animal models in translational medicine: Validation and prediction. New Horizons in Translational Medicine, 2014; 2:05-11

Topol EJ. Failing the public health-Rofecoxib, Merck, and the FDA.N Engl J Med, 2004; 351: 1707-1709

U.S. Food and Drug Administration 2009. Centre for Drug Evaluation and Research (CDER). Guidance for Industry: Drug-Induced Liver Injury (DILI)-Premarketing Clinical Evaluation. (ONLINE) Available:

http://www.fda.gov/Drugs/GuidanceComplianceRegulatoryInformation/G uidances/default.htm. (Accessed on 08 Jan 2016)

Ulatowski LM, Whitmore KL, Romigh T, Vander Wyden AS, Satinover SM, Drumm ML. Strain-specific variants of the mouse Cftr promoter region reveals transcriptional regulatory elements. Human Molecular Genetics, 2004; 13:1933-1941.
Uronis JM, Osada T, McCall S, Yang XY, Mantyh C, Morse MA, Lyerly HK, Clary BM, Hsu DS (2012). Histological and molecular evaluation of patient-derived colorectal cancer explants. PLoS One. 2012; 7(6):e38422

US FDA 2004. Innovation or Stagnation? Challenge and Opportunity on the Critical Path to New Medical Products, Silver Spring, MD, USA: US Department of Health and Human Services, Food and Drug Administration. Available

at: http://www.fda.gov/downloads/ScienceResearch/SpecialTopics/CriticalPat hInitiative/CriticalPath Opportunities Reports/ucm113411.pdf (Accessed 12 Dec 2015)

US FDA 2009. Guidance for Industry, Animal Models Essential Elements to Address Efficacy under the Animal Rule. Silver Spring, MD, USA: US Department of Health and Human Services, Food and Drug Administration. (ONLINE) Available at www.fda.gov/downloads/drugs/.../guidances/ucm399217.pdf (Accessed 12 Dec 1015).

Van Dam D, De Deyn. Drug discovery in dementia: The role of rodent models. Nature Reviews Drug Discovery, 2006; 5:956-970.

Van Zutphen L, Baumans V, Beynen AC. History of animal use. In: Principles of Laboratory Animal Science. Elsevier: Amsterdam (eds)., 2001:02-05

Vedani A, Computer-aided drug design: an alternative to animal testing in the pharmacological screening, ALTEX, 1991; 8:39

Vogel G. A knockout award in medicine. Science, 2007; 318:178-179.

Vogel HG, 2008. Drug discovery and evaluation; Pharmacological assays. Berlin Heidelberg: Springer-Verlag.

Waters, H. 2011. Q\&A: Improving preclinical trials. The Scientist. (Online) Available at: http://www.thescientist.com/?articles.view/articleNo/29581/title/Q-A--Improvingpreclinical-trials [Accessed 08 Jan 2016].

Waterston RH, Lindblad-Toh K. Initial sequencing and comparative analysis of the mouse genome. Nature. 2002; 420:520-562

Wells MY, Williams ES. The transgenic mouse assay as an alternative test method for regulatory carcinogenicity studiesimplications for REACH. Regul. Toxicol. Pharmacol., 2009; 53:150-155.

Wilson SE, Sanders. Invertebrate models for biomedical research, testing, and education, ILAR J., 2011; 52:126-152

Yamada K. Marked prolongation of porcine renal xenograft survival in baboons through the use of alpha1, 3-galactosyltransferase gene-knockout donors and the cotransplantation of vascularised thymic tissue. Nat. Med., 2005; 11:32-34

Zon LI, Peterson RT. In vivo drug discovery in the zebrafish. Nat. ReV. Drug DiscoVery, 2005; 4(1):35-44.

Zosky GR, Sly PD. Animal models of asthma. Clin Exp Allergy 2007; 37:973-88

\section{How to cite this article:}

Siddiqui E, Jagdale P, Ahire K, Jadhav S, Khan SA, Bhosle S, Pal A, Jamdagni P, Chaudhari B. Relevance of Small Laboratory Animals as Models in Translational Research: Challenges and Road Ahead. J App Pharm Sci, 2016; 6 (05): 198-209. 